\title{
Vocal Fold Medialization Procedures for 30 Cases of Glottic Insufficiency: Our Experience
}

\author{
${ }^{1}$ Vicky Khattar, ${ }^{2}$ Sohil D Gala, ${ }^{3}$ Bachi Hathiram
}

\section{ABSTRACT}

Introduction: Glottic insufficiency which is inability to obtain complete vocal fold approximation during phonation is a common cause for dysphonia. Vocal fold immobility, vocal fold sulcus, presbylaryngis, vocal fold scarring are common causes.

Materials and methods: We have studied 30 cases of glottic insufficiency that failed conservative management and underwent surgical intervention. Voice parameters like maximal phonation time (MPT) and voice handicap index (VHI) have been used as assessment parameters along with laryngoscopic examination.

Observations and results: Twenty-one cases had vocal fold immobility, while the rest had vocal sulcus (7), vocal fold atrophy (1), vocal fold scarring (1) as the cause. All cases presented with voice change with few having symptoms of aspiration. Patients were subjected to either vocal fold injection or medialization thyroplasty depending on the etiology and severity, and the outcomes assessed. Majority of our cases showed good amount of improvement on videolaryngoscopy and voice analysis (MPT, VHI scores). Mean MPT scores improved from 7.57 seconds (pre-operative) to 18.83 seconds (final post-operative) and VHI scores changed from a mean of 49.6 to 26.57 . Few had post operative problems like vocal fold oedema, under correction, implant malposition. Four patients needed revision procedures due to suboptimal results.

Conclusion: Selection of the most suitable procedure for each patient, meticulous and precise technique and adequate follow up will promise best results and minimize complications and undesired results in patients of glottic insufficiency.

Keywords: Glottic insufficiency, Medialization procedures, Medialization thyroplasty

How to cite this article: Khattar V, Gala SD, Hathiram B. Vocal Fold Medialization Procedures for 30 Cases Of Glottic Insufficiency: Our Experience. Int J Phonosurg Laryngol 2018;8(1):41-45.

Source of support: Nil

Conflict of interest: None

${ }^{1}$ Assistant Professor, ${ }^{2}$ Senior Registrar, ${ }^{3}$ Professor

${ }^{1-3}$ Department of ENT, Topiwala National Medical College, Mumbai, Maharashtra, India

Corresponding Author: Bachi Hathiram, Professor, Department of ENT, Topiwala National Medical College, Mumbai, Maharashtra, India, e-mail: orlclinics@gmail.com

\section{INTRODUCTION}

Voice is a critical component of personal identity. A clear, pleasing confident voice conveys the positive impression of an adequate personality. Voice disorder can have a significant influence on vocational, social and emotional adjustment of patients. ${ }^{1}$

Glottic insufficiency (GI) is the inability to achieve adequate vocal fold approximation and common causes include vocal cord paresis or palsy, vocal fold scarring, prebylaryngis, sulcus vocalis to name a few. ${ }^{2}$

Management protocols would differ from case to case depending on the symptomatology, etiology, examination findings, severity of the insufficiency and lastly patient acceptance and compliance. A detailed history and clinical examination including video laryngoscopy is a must. Auditory-perceptual evaluation parameters like the $\mathrm{VHI}^{3}{ }^{3}$ grade, roughness, breathiness, asthenia, strain (GRBAS) score and MPT are commonly used and acceptable indices which may help in assessing the severity, decide suitable treatment options and also for treatment monitoring. ${ }^{4}$

Management of glottic insufficiency starts with conservative management and speech therapy failing which a surgical intervention may be attempted. Surgical options include two broad categories of treatments which are injection laryngoplasties and laryngeal framework surgeries either singly or in combination. Adjuvant procedures like arytenoid adduction, cricothyroid subluxation may be needed along with framework surgeries.

We have discussed and analyzed a series of surgically treated 30 cases of glottic insufficiency with respect to their etiology, presentation, treatment, and final outcomes.

\section{MATERIALS AND METHODS}

The study was conducted for 5 years from 2012 to 2016. It included 30 cases of glottic insufficiency of various etiologies. The selected patients were over 18 years of age and had failed to show significant improvement with conservative management and speech therapy. These patients underwent a rigid video laryngoscopic examination to determine the amount of glottal gap and voice indices including MPT, VHI, and GRBAS score were recorded. All these patients were subjected to suitable medialization procedures as per the etiology, severity and 


\begin{tabular}{|c|c|c|c|c|c|c|}
\hline \multicolumn{2}{|c|}{ Symptoms } & $\begin{array}{l}\text { Vocal fold } \\
\text { immobility }\end{array}$ & \multicolumn{2}{|c|}{$\begin{array}{l}\text { Others } \\
\text { (Sulcus, scar, } \\
\text { atrophy) }\end{array}$} & Total & Percentage \\
\hline \multicolumn{2}{|c|}{ Voice change } & 21 & \multicolumn{2}{|c|}{9} & 30 & $100 \%$ \\
\hline \multicolumn{2}{|c|}{ Vocal fatigue } & 16 & \multicolumn{2}{|l|}{5} & 21 & $70 \%$ \\
\hline \multicolumn{2}{|c|}{ Breathy voice } & 12 & \multicolumn{2}{|l|}{0} & 12 & $40 \%$ \\
\hline \multicolumn{2}{|c|}{$\begin{array}{l}\text { Inability to } \\
\text { raise voice }\end{array}$} & 13 & \multicolumn{2}{|l|}{6} & 19 & $63.33 \%$ \\
\hline \multicolumn{2}{|c|}{ Vocal strain } & 12 & \multicolumn{2}{|l|}{6} & 18 & $60 \%$ \\
\hline \multicolumn{2}{|c|}{$\begin{array}{l}\text { Cough on } \\
\text { intake of clear } \\
\text { fluids }\end{array}$} & 4 & \multicolumn{2}{|l|}{0} & 4 & $13.33 \%$ \\
\hline \multicolumn{7}{|c|}{ Table 3: Preoperative VHI scores } \\
\hline \multicolumn{7}{|c|}{ No. of Cases } \\
\hline $\begin{array}{l}\text { Pre } \\
\text { operative } \\
\text { VHI } \\
\text { Scores }\end{array}$ & $\begin{array}{l}\text { Vocal } \\
\text { Fold } \\
\text { Immo- } \\
\text { bility }\end{array}$ & $\begin{array}{l}\text { Sulcus } \\
\text { Vocalis }\end{array}$ & $\begin{array}{l}\text { Scarred } \\
\text { Vocal } \\
\text { Folds }\end{array}$ & $\begin{array}{l}\text { Vocal } \\
\text { Fold } \\
\text { Atrophy }\end{array}$ & Total & Percentage \\
\hline $\begin{array}{l}0-11 \\
\text { (grade 0) }\end{array}$ & 0 & 0 & 0 & 0 & 0 & 0 \\
\hline $\begin{array}{l}\text { 12-28 } \\
\text { (grade 1) }\end{array}$ & 0 & 3 & 1 & 0 & 4 & $13.33 \%$ \\
\hline $\begin{array}{l}29-56 \\
\text { (grade 2) }\end{array}$ & 13 & 4 & 0 & 1 & 18 & $60 \%$ \\
\hline $\begin{array}{l}57-120 \\
\text { (grade 3) }\end{array}$ & 8 & 0 & 0 & 0 & 8 & $26.67 \%$ \\
\hline
\end{tabular}

patient factors. Similar assessment using laryngoscopy and voice indices was done immediate post-operatively and then again at the end of one month and three months after surgery.

\section{OBSERVATIONS AND RESULTS}

Our series had a total of 30 cases which comprised of 21 cases of vocal fold immobility, 7 cases of vocal fold sulcus, and 1 case each of vocal fold atrophy and scarring (Fig. 1).

All the patients presented with voice change. Vocal fatigue, strain, range limitation, and breathiness were other symptoms. Only four patients had symptoms suggestive of penetration/aspiration (Table 1).

Majority of our cases had MPT scores of 6 to 10 seconds and grade 2 severity on VHI Scores. Patients with vocal fold immobility had comparatively poorer results of MPT and VHI Scores (Tables 2 and 3).

A total of 15 patients underwent vocal fold injection with autologous fat and the remaining 15 had a type 1 thyroplasty. One patient who underwent a type

Table 5: Improvement in MPT scores

\begin{tabular}{lll}
\hline $\begin{array}{l}\text { Improvement in MPT at } 3 \text { months } \\
\text { postoperatively compared to preoperative }\end{array}$ & & \\
MPT & Cases & Percentage \\
\hline 5 or $<5$ secs. improvement & 3 & $10 \%$ \\
$6-10$ secs. improvement & 7 & $23.33 \%$ \\
secs. improvement & 19 & $63.33 \%$ \\
16 or $>16$ secs. improvement & 1 & $3.33 \%$ \\
\hline
\end{tabular}

Table 2: Preoperative MPT scores

\begin{tabular}{|c|c|c|c|c|c|c|}
\hline \multirow{5}{*}{$\begin{array}{l}\text { Pre- } \\
\text { operative } \\
\text { MPT }\end{array}$} & \multicolumn{5}{|c|}{ No. of cases } & \multirow[b]{5}{*}{ Percentage } \\
\hline & Vocal & & & & & \\
\hline & fold & & Scarred & Vocal & & \\
\hline & immo- & Sulcus & vocal & fold & & \\
\hline & bility & vocalis & fold & atrophy & Total & \\
\hline $0-5$ & 8 & 0 & 0 & 0 & 8 & $26.67 \%$ \\
\hline $6-10$ & 13 & 4 & 0 & 1 & 18 & $60 \%$ \\
\hline $11-15$ & 0 & 2 & 1 & 0 & 3 & $10 \%$ \\
\hline $16-20$ & 0 & 1 & 0 & 0 & 1 & $3.33 \%$ \\
\hline $\begin{array}{l}\text { More } \\
\text { than } 20\end{array}$ & 0 & 0 & 0 & 0 & 0 & 0 \\
\hline
\end{tabular}

\begin{tabular}{|c|c|c|c|c|c|}
\hline $\begin{array}{l}\text { Type of } \\
\text { procedure }\end{array}$ & $\begin{array}{l}\text { Vocal fold } \\
\text { immobility }\end{array}$ & $\begin{array}{l}\text { Sulcus } \\
\text { vocalis }\end{array}$ & $\begin{array}{l}\text { Scarred } \\
\text { vocal } \\
\text { fold }\end{array}$ & $\begin{array}{l}\text { Vocal } \\
\text { fold } \\
\text { atrophy }\end{array}$ & Total \\
\hline $\begin{array}{l}\text { Vocal fold } \\
\text { Injection } \\
\text { (VFI) }\end{array}$ & 8 & 5 & 1 & 1 & 15 \\
\hline $\begin{array}{l}\text { Type } 1 \\
\text { Thyroplasty } \\
\text { (MT) }\end{array}$ & 12 & 2 & 0 & 0 & 14 \\
\hline $\begin{array}{l}\text { Type } 1 \\
\text { Thyroplasty } \\
\text { with } \\
\text { Arytenoid } \\
\text { Adduction }\end{array}$ & 1 & 0 & 0 & 0 & 1 \\
\hline
\end{tabular}

1 thyroplasty additionally needed arytenoid adduction intra-operatively owing to the large posterior gap and arytenoid asymmetry (Table 4).

All the patients were subjected to a video laryngoscopy and voice analysis using MPT, VHI and GRBAS scores in the immediate postoperative period and then at end of one and three months. Majority of the cases had an improvement of greater than 10 seconds in MPT scores. They also showed good improvement in VHI scores (Tables 5 and 6).

We have compared the preoperative mean MPT and VHI scores to that immediate postoperative and then at end of one and three months. Postoperative speech therapy, resolution of edema may be the factors responsible for final improved outcomes (Fig. 2 and Table 7).

Majority of the patients had a good and favorable outcome. There were a few cases that had complications or undesired results. A total of 7 patients had postopera-

Table 6: Improvement in VHI scores

\begin{tabular}{|c|c|c|c|c|}
\hline $\mathrm{VHI}$ & Pre- & & Post-operative & \\
\hline Scores & operative & Percentage & (3 months) & Percentage \\
\hline $\begin{array}{l}0-11 \\
\text { (grade } 0)\end{array}$ & 0 & 0 & 7 & $23.33 \%$ \\
\hline $\begin{array}{l}12-28 \\
\text { (grade } 1)\end{array}$ & 4 & $13.33 \%$ & 14 & $46.67 \%$ \\
\hline $\begin{array}{l}29-56 \\
\text { (grade 2) }\end{array}$ & 18 & $60 \%$ & 7 & $23.33 \%$ \\
\hline $\begin{array}{l}57-120 \\
\text { (grade } 3 \text { ) }\end{array}$ & 8 & $26.67 \%$ & 2 & $6.67 \%$ \\
\hline
\end{tabular}




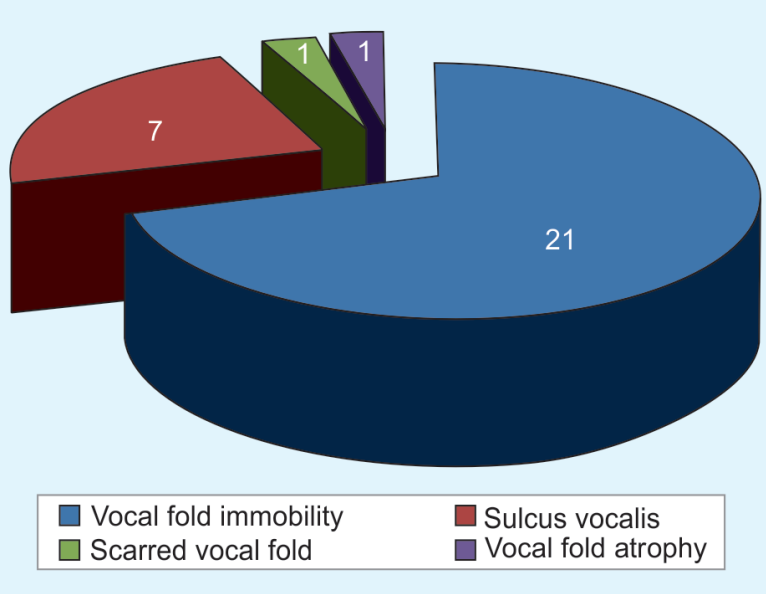

Fig. 1: Distribution of cases

tive vocal fold edema with is a known occurrence with various medialization procedures. Only one of these had symptoms of airway compromise which settled on conservative management with steroids and voice rest. We had suboptimal results in 4 patients either in the form of under-correction or over-correction. We waited for 3 months for labeling the result as suboptimal. Three of these needed a revision procedure. One patient needed a revision due to implant malposition (Table 8).

\section{DISCUSSION}

Glottic insufficiency is a common contributing factor for dysphonia. Impaired vocal fold approximation adversely affects voice outcome, predisposes to aspiration and has a significant impact on quality on life. Vocal fold immobility, sulcus vocalis, atrophy, scarring, presbylaryngis are common causes which are also seen in our case series.

The patients typically present with voice change. Associated symptoms like vocal fatigue, vocal strain, and restricted voice range may be seen. Many patients present with a breathy voice. A secondary muscle tension dysphonia may add to the voice problems. Swallowing may be affected in a few cases. The inadequate glottic approximation can lead to varying amounts of penetration and aspiration. Four of our patients had symptoms of a cough on water intake. On laryngoscopic examination, all these patients had demonstrable penetration (13.33\%) but no frank aspiration. In a study by Rajaei et al. $(n-44)$ of patients with glottic insufficiency $15.9 \%$ cases had a

Table 7: Comparison of mean MPT and VHI scores

\begin{tabular}{lll}
\hline & $\begin{array}{l}\text { Mean MPT } \\
\text { (seconds) }\end{array}$ & $\begin{array}{l}\text { Mean VHI } \\
\text { score }\end{array}$ \\
\hline Preopeartive & 7.57 & 49.6 \\
Immediate postoperative & 13.8 & 36.43 \\
One month postoperative & 17.27 & 30.37 \\
Three months postoperative & 18.83 & 26.57 \\
\hline
\end{tabular}

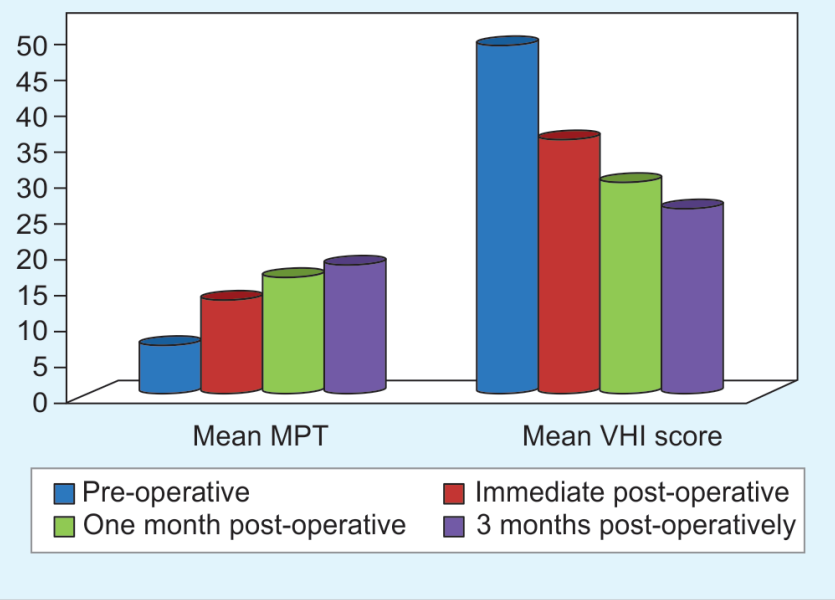

Fig. 2: Comparison of mean MPT and VHI scores

cough on an intake of clear fluid of which $13.63 \%$ had penetration and $2.27 \%$ had aspiration. ${ }^{5}$

A rigid Hopkins telescopic laryngoscopic examination preferably with stroboscopy will tell us about the cause for the glottic insufficiency as well as the extent. Voice analysis is the next step for assessment as well as treatment monitoring. Maximum phonation time (MPT) is the maximum time a person can sustain a tone in a single breath after a maximal inspiration. It usually is greater than 15 seconds and classically reduced in patients with glottic insufficiency. ${ }^{4}$ GRBAS which measures the overall grade of voice problem, roughness, breathiness, asthenia and strain on a scale of 0-3 is another important perceptual scale for analysis. ${ }^{4}$ And lastly the Voice Handicap Index (VHI) which is a quality of life questionnaire consisting of 30 questions dealing with functional, physical and emotional impact of voice disorders. ${ }^{3}$ Patients with vocal fold immobility will usually have poorer results on voice analysis compared to other causes of glottic insufficiency probably owing to the larger glottal gap. Comparatively poorer results were seen in our series of patients too.

Surgical intervention is warranted if conservative treatment and speech therapy fails. Earlier intervention may be attempted for airway protection in case of aspiration or if there is a serious impact on daily and

Table 8: Complication/problems

\begin{tabular}{lll}
\hline $\begin{array}{l}\text { Postoperative } \\
\text { complications/ } \\
\text { problems }\end{array}$ & $\begin{array}{l}\text { After injection } \\
\text { laryngoplasty } \\
(15 \text { cases) }\end{array}$ & $\begin{array}{l}\text { After framework } \\
\text { procedures (15 } \\
\text { cases) }\end{array}$ \\
\hline $\begin{array}{l}\text { Vocal fold edema } \\
\text { Extrusion/ }\end{array}$ & 3 & 4 \\
malpositioning of & - & 1 \\
implant & & \\
Airway compromise & 0 & 1 \\
Overcorrection & 1 & 0 \\
Undercorrection & 2 & 1 \\
Need for revision & 2 & 2 \\
procedures & & \\
\hline
\end{tabular}



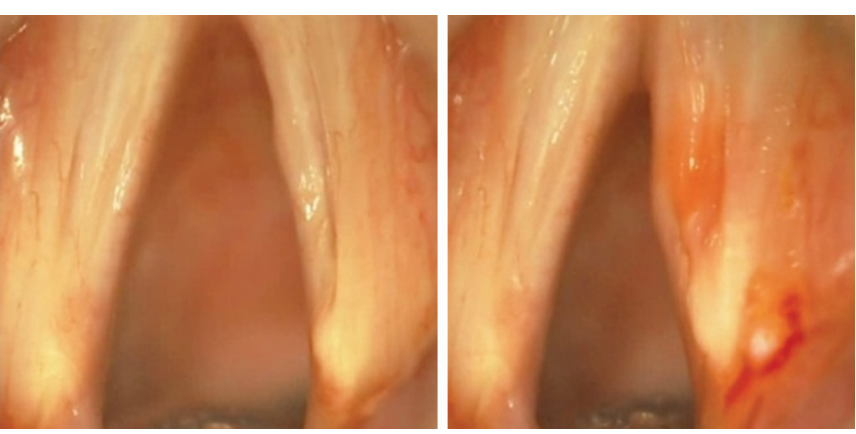

Fig. 3: Right vocal fold sulcus before and after Injection laryngoplasty

professional life. There is myriad of treatment options available, but the decision is based on the symptomatology, etiology, severity of glottic insufficiency, the glottal gap, voice analysis, patient preference and anesthesia considerations. Broadly there are two main treatment categories including vocal fold injection and laryngeal framework surgery.

Vocal fold injection or injection laryngoplasty is usually indicated for mild to moderate severity. It is the treatment of choice where prognosis for recovery is unclear. It involves the injection of various materials into the subepithelial or the paraglottic space depending on the indication and the material used. Various approaches have been tried ranging from direct microlaryngoscopy to the more recent transcutaneous office approaches. Peroral and per nasal approaches have been tried as office procedures. Various materials can be used which may be short lasting, e.g. gelfoam, hyaluronic acid gel or longer lasting like autologous fat, teflon. ${ }^{6}$

We used vocal fold injection in 15 of our patients primarily and in one case after type 1 thyroplasty due to suboptimal results. We used autologous fat using direct microlaryngoscopy under general anesthesia (Fig. 3). The advantages were easy availability and low cost of material, and long-lasting results. Disadvantages included lack of voice feedback and variable level of correction.

Laryngeal framework surgeries involve placement of implants in the paraglottic space through a window into the thyroid lamina to displace the affected vocal medially for favorable phonatory position and complete glottal closure. Various materials like silastic, gortex, titanium have been used. These surgeries are called medialization thyroplasty or type 1 thyroplasty. ${ }^{7}$

We performed type 1 thyroplasties in 15 of our cases using silastic implants (Fig. 4). The advantages were that the procedure could be done under local anesthesia and the presence of voice feedback for determining the extent of medialization. Limitations were technical difficulties in implant carving and the rare possibility of implant-related
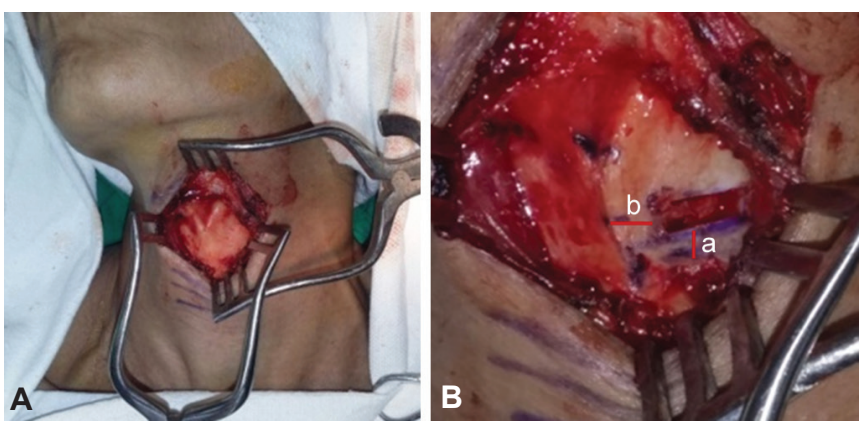

Figs 4A and B: Exposure for Type 1 thyroplasty and window creation for implant $(A)$ distance between lower border of window and lower border of thyroid cartilage $(3 \mathrm{~mm})$; (B) distance between midline and anterior end of window depending on sex of the patient

complications. Procedures like arytenoid adduction can be attempted in conjunction with medialization thyroplasty in cases of large posterior glottic chink where type 1 thyroplasty alone may not give the best results. One of the fifteen type 1 thryoplasties which we performed additionally needed arytenoid adduction.

The outcome of the surgery can be assessed using a degree of patient satisfaction, voice quality, videolaryngoscopic findings, and voice indices (MPT, GRBAS, VHI). We have used MPT and VHI scores for measuring outcomes and results. The above parameters were measured in the immediate postoperative period and then at the end of one and three months. These were compared to the pre-operative assessment parameters.

Few case series have been found in the literature showing the outcome of patients with glottic insufficiency after laryngeal framework surgeries. We have comparable results of outcome in the 15 patients of ours who underwent framework procedures (Table 9).

Few complications or untoward results are possible following various medialization procedures.

Vocal fold injection can present with problems like vocal fold edema and airway compromise which usually can be managed conservatively with anti-inflammatory, steroids and voice rest. Rarely an intervention like a tracheostomy or intubation may be needed. Under correction and overcorrection may give suboptimal results. Granulomas have been reported with Teflon injections. Revision may be needed in a few cases.

Table 9: Comparison of mean MPT and VHI scores with other studies in literature

\begin{tabular}{|c|c|c|c|c|}
\hline \multirow[b]{2}{*}{ Study } & \multicolumn{2}{|c|}{ Mean MPT scores } & \multicolumn{2}{|c|}{ Mean VHI scores } \\
\hline & $\begin{array}{l}\text { Pre- } \\
\text { operative }\end{array}$ & $\begin{array}{l}\text { Final post- } \\
\text { operative }\end{array}$ & $\begin{array}{l}\text { Pre- } \\
\text { operative }\end{array}$ & $\begin{array}{l}\text { Final post- } \\
\text { operative }\end{array}$ \\
\hline Our study & 5.4 & 16.8 & 50.3 & 29.2 \\
\hline Chrobok et al. ${ }^{8}$ & 6.5 & 12.5 & - & - \\
\hline Kanishka et al. ${ }^{9}$ & 4.89 & 13 & - & - \\
\hline Virgilijus et al. ${ }^{10}$ & 6.45 & 15.05 & - & - \\
\hline Anoop et al. ${ }^{11}$ & 3.86 & 16.06 & 87.9 & 28.6 \\
\hline
\end{tabular}


Three of our cases had vocal fold edema post injection laryngoplasty none of which had any airway compromise. These resolved with conservative medical management. Two of our cases needed revision injections due to under correction. In a series by Yung et al. ${ }^{12} 19$ patients underwent vocal fold injection and 5 of them $(26.32 \%)$ needed revision surgeries due to inadequate results.

Framework surgeries can have problems which may be related to the procedure or the implant. Vocal fold edema and airway compromise may occur which can be similarly managed as discussed above. Suboptimal results may be seen in case there is under correction, overcorrection or posterior residual glottic gap. Implant-related problems like malposition, extrusion may be rarely seen. These need revision procedures. Wound infections may occur rarely.

Four of our patients had vocal fold edema post thyroplasty with one progressing to airway compromise which could be managed conservatively. We had one implant malposition which had to undergo revision. We did an injection laryngoplasty in one patient with undercorrection after thyroplasty. In a study by Tucker et al. ${ }^{13}$ of 60 cases of Laryngeal Framework surgeries, 6 had airway compromise $(10 \%)$ and 4 had Implant related problems $(6.67 \%)$, i.e., malposition or extrusion. McCulloch et al. ${ }^{14}$ noticed 2 of his cases had airway compromise for which 1 needed a tracheostomy. A study of 42 cases of Medialization Thyroplasty by Laccourreye et al..$^{15}$ showed $9.52 \%$ cases had airway compromise, $7.14 \%$ had inadequate results, $2.38 \%$ had implant related problems and $7.14 \%$ needed revision surgeries. In a study in Pittsburgh University ${ }^{16}$ the complication rates of Framework procedures were as follows-Extrusion: 0.8\%, Airway compromise: $2.2 \%$, suboptimal results: $4 \%$ and revision rate $6 \%$.

\section{CONCLUSION}

Glottic insufficiency remains a common and fairly easily manageable cause for dysphonia. A detailed assessment followed by choice of the appropriate procedure after the trial of conservative management will ensure good results. Tremendous research and advances have taken place in the surgical methods for treatment. Selection of the most suitable procedure for each patient, meticulous and precise technique and adequate follow-up will promise the best results and minimize complications and undesired results.

\section{REFERENCES}

1. Revis J, Robieux C, Ghio A, Giovanni A.Rev Laryngol Otol Rhinol (Bord). Social consequence of a dysphonic voice, design and validation of a questionnaire and first results. 2013; 134(1):35-41. French.

2. Clark A. Rosen, Hans Leden, Robert H. Ossoff, Blake Simpson, Operative Techniques in Laryngology.Operative Techniques in Laryngology, introduction to glottic insufficiency. chapter 5.1

3. Jacobson BH, Jhonson A, Grywalski C, Silbergleit A, Jacobson $\mathrm{G}$, Benninger $\mathrm{M}$, et al. The voice handicap index. Development and validation. Am J Speech Lang Pathol. 1997; 6: 66-70.

4. Omori K. Outline of voice disorders and examination methods. The Japan Society of Logopedics and Phoniatrics. EditionVoice Examination methods. Tokyo. Ishiyaku Publishers 2009: 36-54.

5. Rajaei A, Ebrahim BB, Fariba M, Mohammad HN. The occurrence of Laryngeal Penetration and Aspiration in patients with Glottal Closure Insufficincy. ISRN Otolaryngology. Vol 2014, Article ID : 557945,5.

6. Clark A. Rosen, Hans Leden, Robert H. Ossoff, Blake Simpson, Operative Techniques in Laryngology. Principals of vocal fold augmentation. chapter 14: 91-95.

7. Clark A. Rosen, Hans Leden, Robert H. Ossoff, Blake Simpson, Operative Techniques in Laryngology. Principals of laryngeal framework surgery. chapter 31: 231-234.

8. Chrobok V, Pellant A, Sram F, Fric M, Praisler J, Prymula R, Svec JG. Medialization thyroplasty with a customized silicone implant: Clinical Experience. Pubmed.

9. Kanishka C, Somnath S, Vedula P S, Sudipta P, Indranil C. Pre and Post Operative voice analysis after medialization thyroplasty in cases of unilateral vocal fold paralysis. Indian J Otolaryngol Head Neck surgery. 2013 December; 65(4): 354-357.

10. Virgilijus U, Ruta P, Viktoras S. Multidimensional assessment of functional outcomes of medialization thyroplasty. Eur Arch Otorhinolaryngol (2005) 262; 616-621.

11. Anoop Raj, Manish Girhotra, Ravi Meher. Medialization Laryngoplasty-AStudy of 15 Cases. Indian Journal of Otolaryngology and Head \& Neck Surgery. Vol 56 No. 4, Oct-Dec 2004.

12. Yung KC, Likhterov I. Courey MS. Effect of temporary vocal fold injection on the rate of permanent medialization laryngoplasty in unilateral vocal cord paralysis patients. Laryngoscope 10/2011; 121(10): 2191-2194.

13. Tucker HM, Wanamaker J, Trott M, Hicks D. Complications of Laryngeal Framework Surgery (Phonosurgery). Laryngoscope 1993;103, 525-528

14. McCulloch TM, Hoffman HT, Andrews BT, Karnell MP. Arytenoid adduction combined with Medialization thyroplasty. Pubmed.

15. Laccourreye O, Madeleine M. Complications of Thyroplasty Type 1 with Montgomery implant. Laryngoscope 09/2005; 115(8): 1411-1417

16. Analysis of Larynegal Framework surgery: 10 year follow up to a National Survey. University of Pittsburgh, Pennsylvania, USA. 